\title{
De la recherche sur les phylactères
}

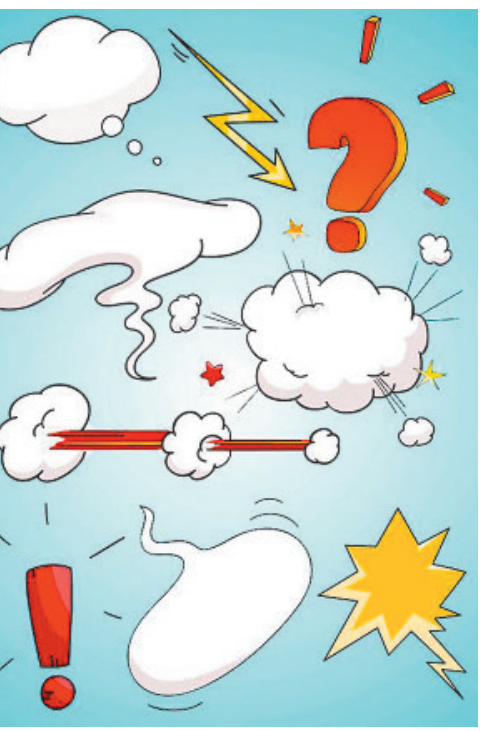

erhard.taverna@saez.ch
Tous les confrères qu'un facteur d'impact insuffisant rend insomniaques vont en pâlir de jalousie. Jamais un article scientifique récent n'aura été autant commenté dans la presse généraliste et spécialisée que cette étude réalisée par une équipe de médecins allemands et publiée dans la revue Acta Neurochirurgica. Cette dernière, parue au printemps 2011, a porté sur 704 cas de traumatismes cranio-cérébraux dus à des agressions et classés selon l'échelle de Glasgow. Les résultats ont été abondamment commentés dans le monde germanophone et anglophone, et même la radio et la télévision en ont parlé. Le journal Zeit Online a même titré: «Asterix academicus - des chercheurs découvrent les avantages d'un procédé d'imagerie».

Marcel Kamp, spécialiste du cerveau et fan d'Astérix a lancé cette recherche. Ses collaborateurs et lui se sont en effet penchés sur les 34 volumes de la célèbre bande dessinée et ont analysé les 690 agressions commises sur des légionnaires romains, des Gaulois, des pirates, des Vikings et même deux Suisses. Il s'agissait d'un gag destiné à être publié dans l'édition spéciale du British Medical Journal à paraître avant Noël. Finalement, l'article a été édité en ligne à Pâques. Les critères diagnostiques étaient les suivants: langues pendantes, représentations graphiques signalisant les degrés de perte de conscience, hématomes liés au port de binocles ou de lunettes. Aucun décès ni atteinte grave à la santé n'a été signalé. Or si l'on sait que les têtes intelligentes se protègent il faudrait encore que les lanières des casques soient bien fixées, ce qui n'est pas toujours le cas chez les soldats de César. Mais les rémissions sont souvent étonnamment rapides, bien que les sandales abandonnées ça et là témoignent de la violence des coups reçus. Ces détails sont évidemment connus des lecteurs au même titre que les éclairs, cloches ou nuages noirs au-dessus des têtes accidentées. La potion magique à base de gui tirée du chaudron du druide Miraculix ne confère pas seulement une force surhumaine, mais a aussi pour vertu d'accélérer la guérison, ce qui devrait intéresser l'industrie pharmaceutique.

D'un point de vue médical, Papa Moll et Globi ont moins d'intérêt. Contusions et doigts pansés ne nécessitent en effet pas de soins intensifs. Tom et Jerry se battent toujours jusqu'à ce que le chat soit collé au mur, mais le passage de la $2 \mathrm{D}$ à la $3 \mathrm{D}$ ne semble pas intéresser les scientifiques. Les blessures sont tout aussi fréquentes chez Spiderman et d'autres super-héros. Batgirl se retrouve en chaise roulante et Wolverine va jusqu'à perdre ses os. Aquaman perd deux fois une main et Thor a le visage couvert de cicatrices. Colonnes vertébrales brisées, jambes et bras arrachés ou éblouissements sont légion. Jusqu'ici, le corps médical ne s'est pourtant pas encore penché sur les prothèses imaginées par les dessinateurs, alors que l'on sait que ces originaux sont souvent bourrés d'idées géniales.

La bande dessinée est un formidable miroir de notre société. L'on ne saurait donc s'étonner que cet art graphique soit fréquemment traité en littérature secondaire. Le $9^{\text {e }}$ art est incroyablement créatif et productif, et les histoires dessinées se sont fortement émancipées depuis Wilhelm Busch. La bande dessinée a marqué bien plus profondément le langage et les habitudes visuelles que l'on ne croit. Elle a vaincu tous ses adversaires idéologiques et religieux, coiffé au pilori les pédagogues et les apôtres de la morale et

\section{«Asterix academicus - des cher- cheurs découvrent les avantages d'un procédé d'imagerie»}

s'est ainsi muée en langage universel. La publicité y a recours car elle permet de vulgariser des informations techniques et médicales complexes. Pour beaucoup d'entre nous, les personnages de bandes dessinées sont plus réels que la réalité. De nombreuses études sérieuses explorent le vaste champ de ce langage graphique. «Dilbert», le personnage inventé par Adam Scott, en dit plus sur le travail de bureau qu'un épais ouvrage de sociologie. «Snoopy» et les aventures de «Calvin et Hobbes» nous emmènent avec brio dans l'imaginaire des enfants. Mais il est difficile de s'y retrouver dans le flot de publications, c'est une jungle qui pousse tous azimuts dont je laisse aux spécialistes le soin de défricher. Les œuvres littéraires de Goethe à Hemingway en passant par Dürrenmatt et Glauser sont racontées en bande dessinée et même «Tintin» sera adapté au grand écran cette année. Le cinéma semble inspirer les dessinateurs et vice versa.

Les aventures d'Astérix et Obélix ont été traduites dans une centaine de langues, en latin (avec glossaire), en suisse allemand, en néerlandais, en créole, et vendus à des millions d'exemplaires. Sans compter les fan-clubs, festivals, lexiques, blogs et autres études consacrées à la bande dessinée. Et comme personne ne veut rester à la traîne de ce succès, il semble logique que les chirurgiens veuillent eux aussi surfer sur la vague.

Erhard Taverna 